\title{
Maternidad en prisión. \\ Situación de los hijos e hijas que acompañan a sus madres compartiendo condena
}

\section{José Gea Fernández}

Universidad Complutense de Madrid

mj_gea@yahoo.es

\section{Resumen}

En el presente artículo se analiza la situación de los hijos e hijas que conviven con sus madres en las cárceles españolas desde la sociología de la infancia. Esta ciencia actúa mediante la aplicación de un enfoque de derechos que permite profundizar en el papel activo de la infancia, atendiendo a las diferentes realidades que pueden vivirse. La situación de los menores de hasta tres años que se encuentran en las cárceles es poco conocida e invisibilizada por las instituciones, puesto que no existen datos oficiales sobre ellos, ni tampoco ningún seguimiento posterior para analizar las posibles consecuencias del encierro. El artículo resume algunos de los resultados del estudio realizado en la Comunidad de Madrid entre los años 2009 y 2012, aplicando el análisis del discurso y el enfoque relacional, que incide en la importancia de conceptos como el de generación, grupo minoritario, género y relaciones humanas como herramientas fundamentales para analizar la realidad infantil y juvenil. Entre las principales conclusiones, puede anticiparse cómo la peor situación que soporta la mujer presa frente al hombre se traduce en unas consecuencias tanto directas como indirectas en sus hijos e hijas, y, además, cómo el trato a la mujer desde conceptos de incapacidad están directamente relacionados con el concepto de los niños y las niñas como seres pasivos y ajenos a la realidad de la que forman parte, puesto que, en este caso, se trata de internos no penados en prisión.

Palabras clave: prisión; derechos; infancia; mujer; maternidad; género; sociología de la infancia 
Abstract. Maternity in prison: Situation of children sharing prison sentences with their mothers

This article analyses the situation of children living with their mothers in Spanish prisons within the framework of the sociology of childhood. This branch of sociology implements a rights-based approach that allows examining in depth the active role of children according to the different realities they experience. The situation of children under three in Spanish prisons is an unknown reality that is made invisible by institutions through the absence of official data on these children in prison and the lack of follow-up to analyse the possible consequences of their confinement. The article summarizes some of the results of a study conducted in the Community of Madrid from 2009 to 2012 by applying discourse analysis and a relational approach that emphasizes the importance of concepts such as generation, minority group, and gender and human relations as fundamental tools for analysing the reality of children and youth. Among the main conclusions, it is found that the worse conditions of imprisoned women compared to men result in both direct and indirect consequences for their children. Moreover, the treatment of these women based on the concept of incapacitation are directly related to the notion of children as passive subjects oblivious to the reality in which they are embedded, in this case being inmates without a prison sentence.

Keywords: prison; rights; childhood; women; maternity; gender; sociology of childhood

\section{Sumario}

1. El enfoque de derechos aplicado a la prevención de libertad infantil

2. Particularidades de los módulos de madres en centros penitenciarios mixtos
3. Análisis de la situación desde los derechos de la infancia vulnerados

4. Conclusiones del análisis y situación actual

Referencias bibliográficas

\section{El enfoque de derechos aplicado a la prevención de libertad infantil}

Entendiendo los derechos humanos como garantías legales universales que protegen a los individuos y a los grupos frente a acciones $\mathrm{u}$ omisiones que puedan afectar a sus libertades y a su dignidad, un enfoque de derechos, en este caso de la infancia, se apoyará en los siguientes cuatro principios:

- La aplicación de la universalidad o principio de la «no discriminación» sin diferenciación de ningún tipo (cultural, de género, clase social, etnia o raza, etc.), aunque dando prioridad a los menos privilegiados y aplicándose inclusive en tiempos de conflicto o desastre natural.

- La atención al interés superior de la infancia, por el que se determina que cualquier decisión, ley o política que pueda afectar a los menores debe tener en cuenta qué es lo mejor para ellos.

- El derecho a la vida, a la supervivencia y al desarrollo: todos los niños y niñas tienen derecho a vivir y a experimentar un desarrollo adecuado. 
- Por último, la participación, a fin de dotar al individuo del derecho a formar parte de la vida política y cultural. Los Estados están obligados a promover dicha participación en todas las esferas.

También es importante resaltar la rendición de cuentas a la que están sujetos los Estados que ratifican los documentos sobre derechos humanos desde la perspectiva de los sujetos como garantes de derechos y no desde la caridad. Así, el Estado debe respetar dichos derechos con una legislación adecuada, protegerlos frente a cualquier violación por parte de un tercero y hacerlos cumplir tomando medidas efectivas y apropiadas.

Es preciso abordar la definición tanto del concepto de derechos humanos como de las premisas que suponen la aplicación de un enfoque de derechos, para tomar conciencia de la existencia de una responsabilidad estatal sobre las situaciones específicas que atañen a los ciudadanos y a las ciudadanas de un país. En este caso, la acción se concreta poniendo el acento en recordar que los menores forman parte activa de la ciudadanía, aunque esto aún siga gozando de un reconocimiento escaso. Así, al colectivo de la infancia y la adolescencia, además de lo recogido en la Carta Internacional de Derechos Humanos, se le aplicará el documento base que complementa dicha carta y alude a dicho colectivo de manera específica: la Convención de las Naciones Unidas sobre los Derechos del Niño (CDN), además de la legislación propia en base a esta materia propia de cada Estado.

A la par de esa cierta difuminación del concepto del niño, de la niña o del adolescente como sujetos de derechos, las ciencias, como herramientas de análisis con el poder que ello les confiere, ejercen también una importante influencia en la labor de invisibilización de este grupo social, siendo parte de ello la sociología como disciplina. Hasta finales de la década de 1980, los menores habían sido muy raramente protagonistas de la investigación sociológica. En aquellos años, prevalecía un enfoque adultocentrista en lo sociológico que menospreciaba la posibilidad de que este grupo pudiera ser parte activa en la construcción de lo social y de que, a su vez, la propia infancia fuera en sí misma un constructo.

En la actualidad, aunque se avanza despacio, los estudios sobre la infancia como etapa de vida a la que atender y revalorizar han experimentado un gran crecimiento, lo que ha obligado a las disciplinas a renovar perspectivas y a redefinir lo que es ser niño o niña en las sociedades contemporáneas (Rodríguez, 2006: 65). Es desde esta renovación y reformulación de la sociología desde donde parte el análisis, reivindicando una sociología de la infancia que implique ir más allá de dar cabida a ese grupo social, el cual, muchas veces, se trata bien desde los problemas de los niños y las niñas o bien entendiendo a estos como problema en sí. Dicha sociología de la infancia parte de los escritos antropológicos de Ruth Benedict y Margared Mead, pioneras en la idea de la infancia como construcción social, pero no será hasta finales de la década de 1980 cuando aparezca esa nueva ciencia de la mano de autores como Cris Jenks o Jens Qvortrup, entre otros (Gaitán, 2006:100). 
En el análisis que nos ocupa, fruto de la investigación desarrollada en la Comunidad de Madrid en el periodo comprendido entre 2009 y 2012, nos hemos apoyado en el enfoque relacional propuesto por Berry Mayall (2002), en el que los conceptos de generación, género y proceso relacional son claves, pero principalmente por su idoneidad al centrar el enfoque en los niños y en las niñas reconociendo que

[...] las personas adultas que más saben de la capacidad de acción moral de la infancia son precisamente las madres, aunque ellas ostentan una posición débil para hablar en su nombre en los espacios públicos y así, en la escuela y en el ámbito político, su estatus moral es más bajo, residiendo el poder en fórmulas psicológicas, en profesionales influyentes, que las utilizan como base de su trabajo sobre, para y con los niños/as. (Gaitán, 2006: 89)

Es precisamente este hecho el que da sentido a la elección de dicho enfoque, pues el material discursivo a analizar proviene tanto de profesionales que rodean a estos menores privados de libertad, como de las propias madres, y es a su vez una forma de legitimar la voz de las personas que más saben de los niños y las niñas: las madres.

Hay diversas formas en las que la infancia es privada de libertad:

- Las justificadas bajo el concepto de protección apoyado en una decisión adulta basada en principio en el interés del menor (por ejemplo: al considerar que existe una situación de riesgo en el ambiente en que se está criando).

- Cuando se trata de razones médicas, basándose, por un lado, en el interés del niño o de la niña, pero también en relación con un «bien común» (ejemplo de ello es el internamiento de menores con necesidades especiales, no sin una discusión subyacente sobre el efecto que la segregación ejerce sobre estas personas y una polémica en ocasiones motivada por la forma de llevar a cabo un diagnóstico).

- Cuando se priva de libertad mediante leyes migratorias. Según la LOEx ${ }^{1}$, se prohíbe que los menores extranjeros no acompañados ingresen en los centros de internamiento de extranjeros. En cambio, diferentes asociaciones de derechos humanos llevan tiempo denunciando cómo, en la práctica, encuentran situaciones en las que, a pesar de que la persona internada alega ser menor de edad, las autoridades concluyen que es mayor de edad mediante un procedimiento que plantea serias dudas, tanto desde el punto de vista técnico como ético (Amnistía Internacional, 2013: 17) .

1. Ley Orgánica de Extranjería.

2. El informe de Amnistía Internacional se apoya en otros documentos que denuncian la inadecuación de estos procedimientos. Por ejemplo, nos referimos al monográfico del Defensor del Pueblo: ¿Menores o adultos?: Procedimientos para la determinación de la edad (2011), o el informe de la Asociación Pueblos Unidos, titulado Miradas tras las rejas: Informe de Pueblos Unidos en el CIE de Aluche en 2011. 
Otros motivos menos comunes son las razones políticas, la acogida momentánea de las criaturas de la calle ante un acto oficial en un país, la toma como rehenes, etc., pero, cuando se habla de privación de libertad infantil, el imaginario colectivo se centra en lo relacionado con el encierro disciplinario, donde predominan las infracciones penales contra el patrimonio y el orden socioeconómico, con un porcentaje muy bajo de delitos violentos. Además, se advierte de que el baremo que se aplica para tipificar determinados actos como delitos es muy estricto en el caso de las personas menores de edad (Cappelaere y Grandjean, 2000), debate que, en el Estado español, se reaviva cada vez que surge un caso puntual de delito violento cometido por una persona menor de edad, lo cual es, como digo, algo puntual frente al alto número de juicios por infracciones contra el patrimonio. Se da entonces una utilización mediática de extrema dureza acerca de esos casos, lo que genera una opinión pública proclive a un endurecimiento de la ley, cuestión que sucede de igual forma respecto al código penal aplicable a las personas adultas, en donde no existe una correspondencia entre la percepción de la sociedad en general y la dureza del mismo. El Estado español tiene una baja tasa de criminalidad en comparación con el conjunto de Europa, en cambio posee una de las tasas de encarcelamiento más altas entre los grandes países de la Unión Europea (Díez, 2006: 17), datos que ilustran esa mayor dureza más aún tras la última reforma del código penal, en la que se incluye la prisión permanente revisable, esto es la legalización de la cadena perpetua, aunque ya anteriormente a esta reforma se hablaba de la existencia de una cadena perpetua encubierta fruto de "condenas no acumulables, pues los hechos se cometieron con posterioridad a la fecha de las otras sentencias, lo que impide someterlos a una interpretación literal de la ley y del criterio de la conexidad procesal a los límites máximos» (Ríos, 2013: 16). Penas eternas de prisión que llegan hasta los cuarenta años de encierro, con lo cual es, de facto, una condena permanente encubierta.

Pararnos a valorar la dureza de los códigos que regulan los castigos que se ejercen desde las instancias acometidas para ello es relevante en este trabajo desde la necesidad de plasmar la realidad que se da tras los muros y en los que desarrollan sus vidas los protagonistas del estudio que se resume, y pone el acento en la vulneración de derechos humanos que se da en las cárceles, imagen que dista y mucho de la idea generalizada de la humanidad de las instituciones penintenciarias de un país democrático.

Así, el último caso de privación de libertad infantil es el que nos ocupa: los niños y niñas que conviven con sus madres encarceladas mientras estas cumplen la pena impuesta en un régimen cerrado. La regulación española permite que los menores de tres años acompañen a sus madres en prisión en módulos adaptados para ello ${ }^{3}$. Son diversas las formas en las que una mujer

3. Hasta 1995, se permitía la estancia del menor hasta los seis años, pero la Ley 13/95 modificó el límite de edad de permanencia de estos niños y niñas en prisión «en primer lugar por la evidencia de que estos niños más mayores eran plenamente conscientes de la realidad en que se encontraban inmersos y por otro lado debido al imparable aumento de la población 
puede acceder a este derecho, ya sea reclamándolo una vez ingresa en prisión y tiene a su hijo o a su hija fuera; en condiciones de detención acompañada del menor; habiendo sida arrestada estando embarazada; o habiéndose quedado embarazada mientras estaba cumpliendo condena.

Siguiendo la estela de la escasez de transparencia e inexactitud de los datos específicos relativos a la infancia ignorada por las estadísticas oficiales, cabe decir que las informaciones sobre el número de niños y niñas que se encuentra en esta situación es inexistente. Por otro lado, también afecta al análisis la gran dificultad que supone para la investigación sobre cárceles la falta de desagregación de los datos penitenciarios por indicadores de género e incluso en algunos cruces también por sexo.

Aún así, los datos recogidos a lo largo de la investigación se apoyan, por un lado, en los citados por personas representantes de Instituciones Penitenciarias, que barajaban un total estatal de alrededor de 200 niños y niñas, mientras que la investigación realizada en 2010, solo en los dos centros que en aquel momento albergaban módulos maternales en la Comunidad de Madrid ya contabilizaba cerca de 100 menores, con lo que la cifra «oficial» de aquel momento nos resultaba escasa. Estas cuestiones reflejan el hermetismo propio de lo carcelario y la invisibilización que rodea la realidad de estas criaturas, siendo también parte de ello las múltiples dificultades encontradas en el trabajo de campo. Los muros de la cárcel se mantienen para todo.

A través de los resultados del análisis, se expondrá cómo este encierro que conlleva un régimen de vida concreto, marcado por una disciplina y un alto entramado institucional, muestra diferentes grados de impacto respecto a los derechos básicos de la infancia, tales como el derecho a la educación, a la salud, de opinión, de vivir en familia y, por supuesto, de protección.

\section{Particularidades de los módulos de madres en centros penitenciarios mixtos}

Para contextualizar la realidad de esta infancia, es preciso comenzar diferenciando entre los espacios que pueden albergar madres con sus hijos e hijas dentro del contexto penitenciario. Son cuatro las formas en las que puede darse esta particularidad: los módulos de madres dentro de prisiones femeninas, los módulos de madres dentro de grandes prisiones mixtas, las unidades dependientes a las que acceden mujeres en régimen de tercer grado y las recientes unidades externas de madres en las que generalmente cumplen condena muje-

penitenciaria femenina que estaba saturando sistemáticamente cualquier esfuerzo de creación de nuevas plazas en centros para madres [...] La segunda conclusión era la ausencia de regulación respecto a la entrada de los menores y la dificultad para contar con datos fidedignos de filiación. En tercer lugar, la falta de apoyo y compromiso de aquellos que ostentaban responsabilidad compartida en el bienestar del menor, es decir, de los servicios de menores de las comunidades autónomas y las fiscalías de menores, quienes relajaron su compromiso, más allá de las tramitaciones formales, ante la mejora de los recursos penitenciarios» (Yagüe, 2006: 148-149). 
res clasificadas en segundo grado ${ }^{4}$ y que suponen un modelo híbrido entre las unidades dependientes y los módulos de madres al uso.

El estudio realizado se centró en analizar la situación de los módulos de madres insertos en grandes cárceles que albergaban tanto a hombres como a mujeres en la Comunidad de Madrid. Debe tenerse en cuenta que la maternidad es omnipresente en todo centro en que residan mujeres, al margen de que exista o no un módulo de madres, ya que esta característica es común en la mayor parte de las presas, entre otras razones, porque el grupo de edad más numeroso es el que va desde los 31 hasta los 40 años, ampliándose en general de los 21 a los 40, por lo que ellas están en pleno proceso reproductivo 5 . Como ya se ha mencionado, se da una escasez de datos en cuanto a indicadores necesarios para realizar estudios desde el género como transversalidad, con lo que resaltamos la ausencia de datos en torno a la maternidad o a la paternidad y el número de hijos e hijas de las personas encarceladas. Aún así, apoyándonos en otros estudios, recogemos que, en 2006, alrededor de un $85 \%$ de las mujeres presas en el Estado español eran madres (Arola, 2010) y que la media de hijos e hijas está muy por encima de la media nacional, puesto que se sitúa en 3,2 (Jiménez y Palacios, 1998: 120). Además, los estudios sociológicos existentes sobre mujeres en prisión (Almeda, 2002 y 2003) apuntan al mantenimiento de roles tradicionales, siendo la mujer la principal responsable de la crianza de los hijos e hijas, aunque en general no se cumpla con el rol tradicional masculino de sustentador económico de la familia, por lo que esta función recae también en ella, con la sobrecarga que ello supone, más aún en casos en los que existe una escasez de recursos e incluso se parte de una situación de exclusión social y vulnerabilidad adquirida.

Centrándonos en los casos en los que la crianza puede desarrollarse intramuros (ya sea en compañía del niño o de la niña nacida en el exterior, ya sea en los casos en los que el propio nacimiento se da una vez la mujer se

4. Preferentemente clasificadas con el artículo 100.2 del reglamento penitenciario, el cual introduce el llamado principio de flexibilidad, adoptando respecto a cada penado un modelo de ejecución en el que puedan combinarse aspectos característicos de cada uno de los grados de clasificación. Ello permite la incorporación progresiva al Medio Abierto de penados clasificados en segundo grado de tratamiento.

También podrán ser destinadas ocasionalmente mujeres en situación de preventivas previa autorización expresa del juez que lleva su caso y, de forma excepcional, alguna mujer clasificada en alguna modalidad de tercer grado recogida en los artículos 82.1, 83 y 100.2 del Reglamento Penitenciario. En todo caso, han de ser mujeres con hijos menores de tres años o embarazadas a partir del sexto mes.

Excepcionalmente, se podrá prolongar la estancia de los hijos y las hijas hasta los seis años o solicitar el ingreso de otro de hasta seis años, aunque serán casos muy concretos que tendrá que valorar y avalar el Equipo de Tratamiento auxiliado por los Servicios Sociales Comunitarios (extracto de la página web de la Secretaría General de Instituciones Penitenciarias. Acceso mediante el enlace http://www.institucionpenitenciaria.es/web/portal/ centrosPenitenciarios/unidadesMadres.html).

5. Según datos de la Secretaría General de Instituciones Penitenciarias para el total de mujeres presas, exceptuando Cataluña, con diligencia propia en materia penitenciaria, en el mes de agosto de 2012. 
encuentra presa), atenderemos a esos módulos de madres. En el año 2005, eran nueve cárceles las que disponían de dicha estancia particular, mientras que, en la actualidad, son tan solo tres ${ }^{6}$. Las políticas en materia de recursos penitenciarios en torno a las necesidades de la mujer en prisión sigue la línea del desfavorecimiento, lo que, en general, supone una escasez de recursos y unas peores condiciones de reclusión para ellas. Una característica intrínseca al encierro femenino es la aplicación sistemática de la dispersión, recurso que, en el caso masculino (o si se aplica expresamente a una mujer por cuestiones de comportamiento o «seguridad»), solo se ejecuta como forma de castigo. Esta dispersión sistematizada es fruto de la escasez de centros que albergan condenadas, cuestión que se asienta sobre el menor número de mujeres encarceladas frente al alto número de hombres ${ }^{7}$. Este hecho supone una vulneración grave del derecho de las personas presas de cumplir condena en lugares próximos a su vínculo social y familiar en beneficio de una reinserción posterior. Así, en el caso de las mujeres, se vulnera dicho derecho, con lo que se dificulta aún más que se mantenga su relación con los hijos e hijas que se encuentran fuera del centro. Pero, en el caso de las madres que cumplen condena acompañadas de sus criaturas, esta dispersión es aún más común, debido a la extrema escasez de centros que permiten esta circunstancia, por lo que, en ocasiones, las mujeres llegan a ocultar su embarazo el mayor tiempo posible para evitar el traslado a un lugar alejado de sus compañeros sentimentales, familias y amistades, ya que la dispersión supone una ruptura de sus vínculos y una desestabilización que va más allá del efecto ejercido en la mujer presa. Este es un claro ejemplo de cómo la cárcel no afecta exclusivamente a las personas que han de cumplir una condena por la comisión de un delito, sino que impregna todo su medio, lo que obstaculiza en muchas (demasiadas) ocasiones la mejora de las relaciones positivas para las personas penadas y alimenta un círculo de exclusión social y aislamiento. Debe, por tanto, valorarse el impacto de la prisión en torno al coste social que supone, más allá de cuestiones únicamente punitivas. En este caso concreto, no solo se vulnera el derecho de la mujer, sino también el del propio menor que cumple condena junto a ella, pues se obstaculiza el derecho a vivir en un hogar, más allá de la propia separación que en sí supone convivir solo con la madre, pues dificulta que exista un sistema de salidas fluidas con el resto de familiares o, simplemente, la posibilidad de

6. Las unidades internas o módulos de madres se encuentran en los centros penitenciarios situados en Sevilla (CP Alcalá de Guadaira), Valencia (CP Picassent) y Madrid (CP Madrid VI - Aranjuez). Esta importante reducción de módulos internos no está acorde con el número de plazas que suponen las unidades externas (también tres: Madrid, Sevilla y Palma de Mallorca), por lo que se puede prever una cierta masificación y lentitud en el acceso a este derecho, y como consecuencia, puede darse la permanencia de niños y niñas en módulos de mujeres no adaptados para albergarlos, con el consiguiente riesgo e incumplimiento de la ley.

Estos datos no incluyen Cataluña, pues en ese caso habría que sumar otra, la del Centro Penitenciario de Mujeres de Barcelona (conocido como Wad-Ras).

7. Según datos de las estadísticas de Instituciones Penitenciarias, en enero de 2016, las mujeres representan el 7,64\% (4.695 mujeres) del total nacional, a excepción de Cataluña, frente al $92,36 \%$ (56.728 presos) que suponen los hombres. 
recibir visitas con frecuencia. Es cierto que, en muchos casos, no existe una relación fluida con el padre, pero cuando esta relación sí existe y él ejerce como tal, mediante la separación, se niega el derecho a ambos de relacionarse de una forma saludable que afecte positivamente al desarrollo del niño o de la niña.

Sobre este alto coste social que supone la prisión, parece existir una gran conciencia por parte de las mujeres en general, muy por encima del caso de los hombres, tal y como muestra la gran diferencia porcentual entre el número de presos y presas (unido a una cultura del delito patriarcal, en la cual se relaciona la masculinidad de forma más positiva con la comisión de delitos como asunción de riesgos, que, en el caso de la mujer, y lo que se entiende por feminidad, más en la línea de la precaución y lo cauteloso). Así, la mujer evita el ingreso en prisión a través del desarrollo de múltiples estrategias, que van desde el aumento de la formación académica para lograr unos mejores puestos de trabajo (se observa en las altas tasas de matriculación en estudios superiores $^{8}$ ), hasta la construcción de redes solidarias basadas en el apoyo mutuo entre mujeres, pasando por estrategias posibilitadas a través de las características propias del cuerpo de la mujer, como pueden ser la donación de óvulos, la maternidad subrogada e incluso prácticas peor valoradas, como el matrimonio de conveniencia o la prostitución. Todas estas estrategias se darán o no dependiendo de la necesidad, de la condición social y cultural y de la inmediatez en la consecución de recursos económicos de sustento (Juliano, 2009).

La cárcel no está adaptada para albergar mujeres, con lo que se agudizan y se perpetúan en ella las diferencias entre sexos, además de que no se tienen en cuenta las necesidades específicas de estas. Son muchas las dificultades que encuentran ellas en prisión y que visibilizan ese desfavorecimiento. Entre otras, podríamos citar: la escasez de centros; la selección de los peores módulos para albergarlas; la aplicación desproporcionada de medidas coercitivas en relación con su grado de conflictividad (menor tolerancia a la indisciplina); la escasez de talleres productivos y la preponderancia a seleccionar los trabajos peor pagados y más tediosos en relación con los que se ofrecen a los hombres; la oferta de talleres de tratamiento de corte sexista centrados en reforzar el rol patriarcal de la mujer como madre o en desarrollar labores tradicionales femeninas, la mayoría de las cuales no están en relación directa con el ingreso en el mundo laboral al salir de la prisión; la escasez de atención ginecológica en el centro; el menor acceso a los espacios comunes; etc. (Almeda, 2002). Todas estas cuestiones se agravan en el caso de los módulos de madres, los cuales se encuentran en una especie de segundo aislamiento del resto de la prisión, ya que los centros deben asegurar la "protección» de estos niños y niñas, lo cual, al no poder desarrollarse por otros medios, se centra en mantenerlos al margen del resto de personas presas para evitar conflictos, y lo que no supone en ningún caso asegurarles una protección en el sentido más amplio del concepto.

8. Los datos del INE respecto al alumnado matriculado en másteres oficiales en el Estado durante el curso 2010-2011 muestran que más de la mitad del alumnado fueron mujeres (un 53,31\%, que suponen 50.622 mujeres). 
Así mismo, no solo la dispersión aplicada por el sistema penitenciario aísla a las madres en prisión acompañadas de sus hijos e hijas, sino que muchas veces son rechazadas y abandonadas por sus propias parejas o por los padres de los niños y niñas. Es preciso resaltar que muchas de ellas provienen de culturas y de hogares profundamente patriarcales, en las que en demasiadas ocasiones han sufrido situaciones de violencia machista, ya sea por parte de sus padres, de sus hermanos y/o de sus parejas sentimentales. Así, ante el «fracaso» en su rol de mujer y la dureza que supone el acompañamiento de una persona mientras cumple condena en prisión, las parejas suelen abandonarlas con una habitualidad pasmosa, mientras que, cuando sucede al contrario y son los hombres los que se encuentran en prisión, son precisamente sus parejas mujeres las que les sirven de sustento emocional y económico. Esta desatención hacia ellas provoca consecuencias a nivel de recursos económicos, puesto que se encuentran en una situación de vulnerabilidad total dentro de la prisión, pero sobre todo supone un impacto emocional tremendo que afecta tanto a su autopercepción como al estado de ánimo que tendrá consecuencias también en el desarrollo de la crianza y la relación con su hijo e hija. Todo ello debería recibir una atención especial por parte de la Administración para atender a las circunstancias personales de las mujeres previas al ingreso en prisión. Es preciso, dada la alta incidencia de la violencia machista sufrida con anterioridad a la condena, que se desarrolle y se aplique un protocolo de atención a estas mujeres de cara a una futura reinserción en su lugar de origen. Y, por otro lado, es necesario desarrollar programas de atención en los casos en que sea preciso con terapias que suplan y eviten la sobremedicalización que se aplica a la mujer en prisión, tendencia que va íntimamente ligada con la concepción histórica de relacionarlas a ellas con la enfermedad mental (histéricas, locas y/o brujas), que no ha sido más que otra forma de ejercer la dominación y el control social sobre las mujeres como agentes sociales activos. En esta línea, se aprobó, en 2008, el Programa de Acciones para la igualdad entre mujeres y hombres en el ámbito penitenciario9 , que incluía más de 120 medidas. Entre las principales, destaca la «atención a las mujeres víctimas de violencia de género, mediante la creación de un grupo multidisciplinar de expertos que ha elaborado un manual para mujeres con un historial de violencia de género, denominado Ser mujer. es» (Yagüe, 2012). Para el estudio que nos ocupa, además de esta medida, nos interesan otras, como, por ejemplo:

[...] el programa piloto de mediación familiar: desarrollado en Andalucía en un centro penitenciario con el fin de facilitar las relaciones entre las madres y los hijos/as así como el regreso al entorno familiar; la creación de la Unidades Externas de madres; la elaboración de un sistema de indicadores para evaluar las condiciones en que se desarrolla la ejecución penitenciaria de las mujeres respecto a los hombres. (Yagüe, 2012)

9. http://www.institucionpenitenciaria.es/web/export/sites/default/datos/descargables/publicaciones/Programa_para_la_igualdad_accesible.pdf 
Pero, a pesar de haberse desarrollado dicho programa, este terminó su vigencia en 2011 con el cambio de gobierno, lo que produjo una parálisis en la incorporación de medidas de igualdad en el ámbito penitenciario. Por otro lado, actualmente no se dispone de información sobre el grado de implantación ni sobre los resultados alcanzados con las acciones que componen el programa. De hecho, se está finalizando un informe de seguimiento del mismo en su periodo de implementación 2008-2011, en el que se señalan dificultades por la falta de información al respecto. En ese programa, ya se observaba, además, una cierta mezcla en el abordaje de las acciones para la igualdad, de tal forma que, por un lado, se permanecía en un cierto paradigma de simple "equiparación» femenina a la situación de los hombres y, por otro, se daban tímidos pasos hacia una consideración más integral de la perspectiva de género, como el abordaje y la atención a la realidad específica y diferencial por sexos en el contexto penitenciario. Esto último consiste en incorporar una mirada no androcéntrica, alejada de la constante "neutralidad", en el contexto penitenciario, que se ha traducido siempre en que la presencia mayoritaria de varones eclipsaba cualquier mínima atención a la realidad y al contexto de las mujeres encarceladas (Ballesteros y Almeda, 2015: 170-171). Aún así, como se ha mencionado, el programa ha quedado prácticamente sin implementar y se ha reducido a la realización de algunos talleres de prevención general de violencia machista.

Para cerrar este apartado centrándonos de forma exclusiva en las particularidades de los módulos de madres, es preciso determinar cómo son esos módulos en los que residen niños y niñas y qué cuestiones regimentales o de tratamiento les hace diferentes al resto de la prisión.

Arquitectónicamente, los módulos de madres son iguales a los del resto de la prisión, aunque dentro de ellos se realicen adaptaciones de los espacios, se dediquen estancias para escuela, actividades formativas o juegos infantiles — como explica Yagüe sobre la unidad de Alcalá de Guadaíra—, o se arreglen los espacios exteriores:

[...] el patio cuenta con bancadas de azulejos sevillanos, parterres, decoración de los muros con motivos infantiles, plantas, juguetes de intemperie, piscinas desmontables en periodo veraniego, etc., dando al conjunto un aspecto similar al de las plazas típicas existentes en la ciudad, como lugares propios para el paseo y el esparcimiento infantil. (Yagüe, 2006: 172)

Lo que la ley exige en el artículo 17.5 del Reglamento Penitenciario es que las unidades de madres cuenten con un local habilitado para guardería infantil y que estén separadas arquitectónicamente del resto de los departamentos. En este caso, debe diferenciarse entre los tres centros que en la actualidad cuentan con unidad interna de madres, pues nada tienen que ver las condiciones de un centro como el sevillano que analiza Yagüe, que alberga solo a mujeres y cuenta con 83 celdas más 7 complementarias, con los recientes modelos arquitectóni- 
cos centro tipo o macrocárceles ${ }^{10}$, más relacionados con los centros ubicados en Valencia y Aranjuez, donde se encuentran las otras dos unidades de madres ${ }^{11}$.

En el caso concreto visitado, Madrid V, Soto del Real, el modelo era el de centro tipo (con 1.008 celdas más 174 complementarias), además de ser de alta seguridad y con prevalencia de régimen preventivo. En este caso, se cumple con las premisas del reglamento penitenciario, ya que cuenta con un local separado habilitado como escuela infantil, y el módulo de madres está separado arquitectónicamente del resto, pero, como se ha expuesto, esto no hace que la estructura del módulo en sí sea diferente a la del resto de módulos de la prisión.

El módulo de madres disponía de una planta superior donde se encontraban dispuestas las celdas (en estos módulos, se les llama "habitaciones", en un intento de normalizar la situación), así como de una planta inferior compuesta por una «sala o zona de estar» y un comedor junto con la garita donde están las funcionarias de vigilancia y alguna otra sala para la trabajadora social o educadora, el médico o similar. Comunicando con la sala donde pueden estar las presas como espacio común, se encuentran un patio y una construcción añadida, en este caso utilizada como ludoteca y, en otros módulos, dedicada a labores de peluquería u otras actividades lúdicas o formativas. Hay deficiencias importantes en materia de adaptación del espacio para que convivan allí menores. Las más relevantes giran en torno a la no eliminación de barreras arquitectónicas, como son las escaleras o los enrejados. También es muy importante resaltar el sistema de cierre automático de puertas, el cual no atiende a la espontaneidad de movimientos de una criatura de entre 0 y 3 años.

Los altos techos, los materiales de construcción y la propia arquitectura del módulo provocan que exista un gran eco y todo pequeño ruido se escuche muy alto. Así, las conversaciones entre treinta o cuarenta mujeres hacen que exista un constante ruido de fondo, lo que, junto con las continuas llamadas por megafonía, no proporciona el ambiente de tranquilidad que precisa un recién nacido o un niño o niña de estas edades, puesto que ni a nivel de derechos en cuanto a salud se refiere, se respeta el sueño necesario para el descanso del sistema nervioso de los menores. Además, ello les puede perjudicar también respecto a la audición, como ocurre en el caso de personas adultas presas (Valverde, 1991). Así, algunas madres hablan acerca de cómo esto afecta al descanso y al sistema nervioso de sus criaturas desde que están en el centro. La temperatura tampoco está bien regulada, cuestión que aseguran las profesoras de la escuela externa, al detectar que las madres que están en prisión abrigan en demasía a

10. «Esta nueva estructura se configurará como una pequeña ciudad penitenciaria y autosuficiente con capacidad para alrededor de 1000 personas en celdas individuales, lo que exigirá el traslado a zonas alejadas de las ciudades donde existen extensiones suficientes de terreno» (Ballesteros y Almeda, 2015: 166)

11. El CP Valencia, Picassent, alberga 1329 celdas más 239 complementarias, y el CP Madrid VI Aranjuez cuenta con 936 celdas más 135 complementarias, lo que les diferencia sustancialmente de un centro como el de Alcalá de Guadaíra, en número de celdas, de personas que alberga (entre 120 y 150) y en el hecho de ser centros mixtos, con presencia minoritaria de mujeres respecto al total de internos, mientras que el de Sevilla es exclusivamente femenino. 
sus hijos e hijas fruto del frío que hace en el módulo (este centro en concreto se encuentra en la sierra de Guadarrama, en Madrid, donde las temperaturas son muy bajas en invierno).

En cuanto al espacio, normalmente se ocupa una celda por madre e hijo o hija, excepto cuando se trata de una embarazada, en cuyo caso le acompaña otra mujer por si surgiera alguna complicación en los momentos de cierre de celda. Estas celdas disponen de un inodoro y de una bañera, así como de una cama y, en principio, se pueden pedir barreras o cunas para la misma, pero las presas contaban que existían problemas para acceder a determinados materiales, lo cual era fuente de conflicto, puesto que este aspecto no estaba gestionado debidamente. El principal inconveniente de la celda (además de la escasez de espacio) es la ausencia de muebles con puertas donde poder guardar elementos peligrosos para que no estén al alcance de los menores, como son, sobre todo, los productos de limpieza, además de la cercanía de algunas escaleras en las cuales no hay rejilla de seguridad, así como los cierres automáticos de la puerta de la propia celda.

Se observa, entonces, que no hay una preparación especial del módulo para que pueda ser habitado por niños y niñas (más allá de la decoración de las paredes con motivos infantiles), pero sí existen unos requerimientos de la ley para que tenga lugar esta situación en un centro penitenciario. Exigencias que, en este caso, sí se cumplían, como, por ejemplo: la existencia de una escuela infantil dentro del propio centro, a la que se pretende que acudan los bebés lo antes posible hasta aproximadamente los 12 meses. Desde el centro también se intenta que asistan a la escuela infantil externa de la localidad más cercana, en pro de una mayor normalización y de establecimiento de contacto con el exterior de la prisión. Sobre la escuela infantil interna, debemos apuntar en positivo la ratio tan baja entre trabajadoras y menores, con lo cual se pueden realizar unas clases especializadas y establecer una relación fluida con las madres. Por lo que se refiere a la escuela infantil externa, debe, por tanto, existir un convenio previo entre el centro penitenciario y dicha institución docente, para que se aseguren unas plazas en cada curso escolar. Tienen que establecerse unas visitas del pediatra o la pediatra del ambulatorio de la población más cercana a la prisión para que asista a las criaturas en el propio módulo. También se requiere un convenio de colaboración con alguna organización que se encargue de organizar actividades con los niños y las niñas fuera de la prisión los fines de semana y en periodos estivales. Y, por último, «no podrán ser aplicados medios coercitivos como el aislamiento provisional, la fuerza física personal, las defensas de goma o los aerosoles de acción adecuada a estas internas» (artículo 37.2 del Reglamento Penitenciario). En cambio, una cuestión que se resaltaba durante la realización de la investigación en los discursos de diferente tipo de funcionariado, era la adecuación de las visitas al tipo de visita familiar en persona, puesto que consideraban que, para los menores, comunicarse a través de un cristal era algo violento y traumático, pero en la actualidad debe recalcarse el endurecimiento de esas visitas, recortándose a dos las visitas familiares al mes e introduciendo la posibilidad de comunicarse con el niño o la niña por locutorio 
(a través del cristal). Esto supone, por un lado, una vulneración del derecho de protección del menor y, por otro, un ejemplo más de cómo el derecho de controlar que tiene la institución carcelaria está por encima de los derechos de estos niños y niñas. La seguridad por encima del tratamiento.

\section{Análisis de la situación desde los derechos de la infancia vulnerados}

Como se ha argumentado, son muchos los derechos de la infancia que se vulneran en esta situación concreta de privación de libertad y que, en cambio, el Estado español debiera preservar como país adherido a la Convención sobre los Derechos del Niño.

El artículo 9 de la CDN aborda la cuestión de la separación del niño o niña del ámbito familiar, en concreto de sus padres. En este caso, la decisión de que el menor acompañe a la madre o no, recae principalmente en el derecho de la mujer, puesto que, en la regulación de esta situación, se alude a atender al interés superior del niño.

Pero son diversos los aspectos a tener en cuenta cuando hablamos del ámbito doméstico, pues este artículo lo centra en las figuras paterna y materna, obviando nuevas formas de parentesco y excluyendo a figuras como son los hermanos y las hermanas u otros familiares que ejercen de cuidadores frente a un posible desentendimiento, por ejemplo, en este caso, del padre. Es por ello que, desde el análisis, consideramos que existe una cierta vulneración de la obligación del Estado español de velar por la no separación de la criatura, además de la figura paterna en este caso, del ámbito familiar en un sentido más amplio, necesario para el correcto y completo desarrollo del menor.

En el estudio, las relaciones de estos niños y niñas con otras personas se han dividido en dos tipos de redes: la red primaria, en la que la figura principal es la madre, con la que generalmente se desarrolla un fuerte vínculo, agudizado por la situación de mutua dependencia dada la dureza del encierro, pero en el que, además, se incluyen otras figuras familiares, como el padre en caso de existir una relación cercana, los abuelos y abuelas (generalmente maternos) o los hermanos y hermanas, los cuales suponen un importante agente en el desarrollo infantil, todos ellos sujetos en su relación con un estricto protocolo que normativiza y limita el contacto entre ellos, más aún en el caso de los otros familiares niños o niñas, sobre los que, además de imponerse las restricciones del régimen de visitas de la prisión, se imponen las decisiones adultas de aquellos que les rodean en lo que respecta a si debe o no, darse la posibilidad de relación entre los demás parientes menores de edad (primos, primas, etc.). Debe atenderse también a la alta tasa de personas extranjeras que cumplen condena en este país, en cuyo caso esa red primaria queda prácticamente reducida a la madre ${ }^{12}$.

12. La situación de la mujer extranjera en prisión requiere de un análisis propio en diversos aspectos, dada su complejidad y la diversidad de situaciones, por lo que no se entrará a tratar en profundidad en este artículo, pero puede ampliarse información en el único estudio que aborda concretamente esta temática desde una perspectiva sociológica y de derecho: 
La red secundaria se compone por el resto de relaciones no familiares que conforman la realidad de estos niños y niñas: las otras madres presas y sus hijos e hijas, las educadoras infantiles, las personas voluntarias de la ONG con la que existe el convenio de colaboración, la educadora social, el pediatra o la pediatra y el funcionariado de vigilancia. En esta red, las relaciones más positivas son las que se generan entre educadoras y menores, puesto que aquellas aportan un discurso crítico con el medio carcelario y activo en cuanto a la función social del niño o niña en su propia realidad. En cambio, las relaciones más negativas son las que se dan con el funcionariado de vigilancia, no porque tengan que ser necesariamente negativas todas ellas, sino por depender de la voluntariedad de las funcionarias el cómo se den estas relaciones, es decir: no existe un protocolo de actuación en cuanto al trato del funcionariado hacia estos niños y niñas, que, no se debe olvidar, no están "cumpliendo condena alguna». Así, las funcionarias que ocupan estos puestos no tienen preparación específica para ello, ni una motivación o una sensibilización especial para tratar con el colectivo de la infancia, sino que se accede a la plaza por solicitud (o administración) en relación con la antigüedad laboral. Todo esto da lugar a muy diferentes tipos de relaciones, que van desde la empatía hacia los hijos y las hijas de las mujeres presas, hasta el ignorar la presencia de estos menores, pasando por ejercer acciones de violencia simbólica y/o explícita ante ellos:

Yo creo que uno de los aspectos más negativos que hay son ciertos hechos puntuales que ponen de manifiesto y en evidencia que están donde están. Por ejemplo, un recuento es uno de esos actos, el cacheo es otro. Hay muchas formas de obrar y aquí se pone de manifiesto el estilo de las funcionarias. Algunas hacen un recuento que ni te enteras de que es un recuento. Yo lo veo y les digo: «QQué rápida eres $\mathrm{H} ! »$. Y me responde que ella mira y ya está, no necesita más, precisamente para no hacer de ello un acto remarcable. El cacheo pues lo mismo. Hay quien lo hace con mucha delicadeza, con mucha profesionalidad en ese sentido, y hay quien actúa con muy mala leche, hablando mal y pronto, perdona la ordinariez, pero porque ese día le pilla torcido y entonces entra en el cuarto, corre la cortina y empieza a tirar al suelo absolutamente todo lo que hay en la estantería, la ropa, del niño y de la madre, da la vuelta al colchón y empuja las cosas con el pie. Cuando un niño ve eso... Para mí, eso es un acto de violencia contra tus bienes. (Entrevista a voluntaria de ONG interna)

Aunque no son este tipo de registros (cacheos) los únicos que se llevan a cabo, sino que también se realizan sobre la propia persona, y ese acto carece de nuevo de un protocolo explícito para cuando se trata de registrar a un bebé o a una criatura menor de tres años.

¿Cómo lo hacemos? Pues nada, cogemos al bebé, le palpamos mientras jugamos un poquito con él, le pasamos la raqueta como un jueguecito. Él se lo toma muy 
bien, porque tú lo haces de una manera muy divertida, le das cuatro besos, él a ti te da cinco y ya está, y asi [voz apenada], yo así es como lo he hecho. Yo no sé las compañeras cómo... [silencio]. (Entrevista a una funcionaria de vigilancia)

Son varios los derechos vulnerados en este caso, tales como el derecho a la protección de los niños y las niñas privados de su medio familiar, pues, aunque estén junto a la madre, se encuentran fuera de un medio normalizado; el derecho a no ser objeto de injerencias en su vida privada y a no ser atacados en su honor, y el derecho a no ser sometidos a tratos crueles, inhumanos o degradantes. En este caso, la funcionaria entrevistada relata un primer registro superficial, pero si el centro tuviera dudas, se pasaría a un segundo cacheo de mayor intensidad, que entraría sin duda en la categoría de trato degradante.

Un concepto básico también para el enfoque relacional es el de generación, pues concierne a la forma en la que se distribuye el poder en generaciones coexistentes. Es algo hasta ahora casi inherente al grupo social de la infancia el poseer un poder muy por debajo del que tienen las personas adultas, pero, en este caso, son diversos los mayores que lo ostentan. Además, ello se da de una forma muy jerarquizada: por encima de las niñas y los niños, las madres; por encima de las madres, el resto de los adultos que las rodean (educadoras, médicos, psicólogas, inclusive parte del voluntariado), y, en la posición más elevada, plasmándolo mediante un alto y marcado ejercicio de poder, estaría el funcionariado de seguridad. Este ejercicio de fuerza se ve reflejado en la escasa presencia del juego libre, básico para el desarrollo en la primera infancia, y esto se debe a un exceso de normatividad, a la falta de facilidades por parte del centro de disponer de espacios adecuados para que estén los niños y las niñas en contacto con, por ejemplo, un jardín, un huerto, unos columpios, el agua, etc., y, en caso de disponer de estos espacios, no se facilitan las salidas del módulo tal y como se ha dicho con anterioridad, pues es precisamente este uno de los que se encuentra más aislado del resto de las instalaciones. Así, la extrema jerarquía que regula el día a día del módulo produce situaciones tales que en ocasiones hasta las propias madres son las que limitan en exceso el juego del menor, para evitar llamadas de atención por parte de las funcionarias.

Como se ha visto en relación con la situación general de la mujer presa, otro concepto necesario es el de género, el cual es transversal al estudio. Los módulos de madres (de mujeres) carecen de este enfoque, por lo que no se atiende a las necesidades de las recluidas, lo que provocará que, directa e indirectamente, los hijos e hijas se vean afectados por esa ausencia de políticas adecuadas (ejemplo de ello es la escasez y, en ocasiones, la deficiente atención ginecológica, lo que, en el caso de tratarse de mujeres embarazadas, afecta al feto y, por ende, a su vida y a la protección de la misma, con lo que queda cuestionado en este caso el derecho a la salud tanto de la madre como del hijo o la hija ${ }^{13}$ ). Además, en un

13. Quedaría cuestionado también el «derecho a disfrutar del más alto nivel posible de salud y a tener acceso a servicios médicos» (artículo 24 de la Convención de los Derechos del Niño), al restringirse las visitas del pediatra a días concretos, a no ser que, por la gravedad, 
análisis más amplio, es importante resaltar cómo la consideración de los niños como seres en camino de ser, es decir, carentes de la calificación de personas, con todo lo que ello implica, se relaciona con la visión que se da de la mujer presa y, más aún, en el caso de las madres a las que se despoja de la capacidad de ejercer como tales, dado su fracaso social en su rol de mujeres y de progenitoras. Al hablar de las criaturas y de las madres, aparece, en ambos casos, el concepto de incapacidad, justificando posturas paternalistas que acaban siendo la base de ese despojar a la mujer de su capacidad como tal, y del niño o la niña como agente activo que percibe los procesos que le rodean. Quedarían aquí en entredicho los derechos de participación.

Y así, entraría en este punto del análisis la necesidad de situar al grupo social de la infancia en una minoría atribuida por su edad, pero sin olvidar que la forma en la que se están desarrollando los primeros años de estos niños y niñas les hace parte de otra minoría: la de las personas presas o ex-presas, lo que supone una serie de características a tener muy en cuenta a la hora de valorar el posible impacto del encierro, pues diferentes estudios sobre las consecuencias de la prisionización hacen referencia a la pérdida de habilidades adquiridas y a la autonomía. En este caso, será más visible en los menores nacidos fuera de la cárcel, pues será en ellos en los que se observará el retroceso, por ejemplo, en la pérdida del control de esfínteres, en la capacidad de hablar, en la normalización del sueño, en la alimentación, en episodios de estrés, etc. Cuando se trata de los nacidos en el centro, se observa en ocasiones un cierto retraso en la adquisición de algunas habilidades, pero en ambos casos puede darse una dificultad posterior al encierro, en la capacidad para exponerse a espacios abiertos, cuestión común también a las personas adultas una vez son liberadas de la prisión, tal y como nos explicaban desde casas de acogida a las que van las madres sin recursos después de salir de prisión:

Hay muchas cosas que han dejado de tener dentro de prisión, que pierden, pues, por ejemplo, desde que llegan y no apagan la luz, una cosa tan... Claro, porque es que allí la enciende y la apaga un funcionario o... sobre todo lo notas mucho al principio de que no son capaces de tomar decisiones por ellas mismas, o sea, siempre te preguntan si pueden, no pueden... Pues eso, como han tenido su vida tan supeditada que es "puedes mantener relaciones sexuales tal día a tal hora en un vis a vis», "puedes hacer tal cosa tal día y a tal hora». ¿Sabes? Es todo tan, $\tan , \tan . .$. Ellas mismas, antes tomarían sus propias decisiones y llega un momento en que no son capaces de tomarlas y que les cuesta mucho actuar por su cuenta... También mucho miedo al exterior, quiero decir, por ejemplo, cuando cogen el metro, cuando tal, cuando ven mucha gente a su alrededor, pues tienen ciertos miedos, hasta que poco a poco se van familiarizando con la vida en libertad y los van perdiendo... Y cuando los niños salen de prisión, las primeras veces gracias a permisos, también se nota mucho. (Entrevista a trabajadora de ONG externa)

considere el funcionariado de seguridad (ejerciendo una figura médica que no le corresponde ni está capacitado para ello) que debe pedirse una visita al médico general del centro y este estime pertinente el traslado del niño o de la niña a un centro hospitalario, cuestión que está regimentada y suele realizarse correctamente. 
Pero si hay un hecho clave en la experiencia de estos niños y niñas como parte de su condición de presos, es el momento en que debe tener lugar la separación de la madre. Con suerte, esta puede no darse si ella logra el tercer grado y, con él, el acceso a un medio abierto o semiabierto en compañía de su hijo o de su hija, pero a veces este no es el caso. En principio, se pretende que dicha separación se realice de forma progresiva, a fin de favorecer las salidas al exterior con los familiares a cuyo cargo vayan a quedar y disminuir el tiempo que pasen en el centro junto a su madre. Pero, dados los perfiles mayoritarios, esa situación no es la más común, puesto que el abandono por parte de la familia, la escasez de recursos económicos para hacer frente a los desplazamientos o el encontrarse en otro país (presas extranjeras) puede suponer una separación brusca que solamente es posible suavizar en caso de que la criatura esté al cuidado de amigos o familiares algo conocidos (la mejor opción) o inclusive mediante un hogar de acogida temporal con el que pueden empezar a congeniar antes de la separación definitiva en caso de producirse. Dichas familias se seleccionan previo examen de sus características sociales, procurando que cuenten con hijas o hijos propios y no alberguen expectativas de adopción. A ese programa de hogares de acogida se deriva a los niños y a las niñas de mayor edad que precisan de esta oportunidad, y en ningún caso la familia selecciona al menor. También se prevé que pueda hacerse un acogimiento formal temporal cuando la condena de la madre se prolongue más allá del cumplimiento de la edad máxima de permanencia de su hijo o de su hija (Yagüe, 2006: 174). Por el contrario, la opción más impersonal y negativa supone alargar el proceso de institucionalización, en esta ocasión endurecido con la ausencia de la madre e ingresando al menor en un centro de protección. Huelga explicar la crudeza de la separación, teniendo en cuenta la corta edad de los niños y de las niñas que precisan del cuidado materno, y más aún en los casos en que, debido a la especial situación, se ha instaurado entre ellos un vínculo afectivo muy fuerte, fruto de la dureza del encierro y del miedo de la madre a la futura separación.

Sobre el poco respeto que se da en demasiadas ocasiones a los procesos de duelo y separación, aportan mucho las experiencias de las educadoras externas, las cuales no entienden que se envíe a estos niños y niñas a escuelas externas en beneficio de una integración y de una normalización y, en cambio, no se respeten los procesos propios de los cursos escolares y los beneficios que aportarían para vehicular esa separación de una manera educativa con un enfoque psicológico y empático basado en la importancia del apego, a través de las propias tutoras, a las que están también íntimamente unidos, explicando y adelantando poco a poco, y de una forma comprensible para los niños y las niñas, el proceso al que se van a enfrentar.

A veces, las leyes no tienen ni pies ni cabeza, ¿̨no? Las madres pueden permanecer con sus niños y supongo que allí en la unidad de madres hasta los tres años, desde que es bebé hasta los tres. Entonces eso es inamovible. Pero si lo que estamos intentando hacer, y es por lo que vienen a una escuela fuera del centro 
penitenciario, es la ¡normalización!, eso no es un criterio de normalización. Lo normal es que ese niño que empieza un curso escolar con su grupo de clase lo finalice. (Entrevista a educadora infantil y psicóloga)

El artículo 29 de la CDN habla de cómo la educación debe orientarse, además de a desarrollar la personalidad y las capacidades del niño o la niña, a inculcarle el respeto a los derechos humanos elementales. Encontramos aquí una cierta contradicción de nuevo.

Hechos como este vuelven a manifestar la preponderancia del régimen ante el tratamiento, sin considerar los derechos de estos niños y niñas, pues al final, para la institución, son un objeto extraño con el que no se sabe muy bien cómo actuar, hacia el que se reconoce su inocencia de palabra, pero que, sin embargo, constituye parte de la masificación de las cárceles españolas y no se contempla el cambio necesario en la política penitenciaria, aún estando estos menores en los centros. Es habitual la protesta de la poca implicación y coordinación de los servicios sociales con los departamentos de tratamiento de los centros penitenciarios. Esto tiene que ver con la escasez de recursos en materia social, además de con la dificultad con que se trabaja desde departamentos estancos, dado el exceso de burocratización de sistemas que, desde este punto de vista, precisan de una flexibilidad y de una adaptación, al tratarse de problemáticas humanas y sociales, con lo que tienen de cambiantes e inmediatas en muchas ocasiones.

\section{Conclusiones del análisis y situación actual}

El interés superior del menor es uno de los principios rectores de la Convención de los Derechos del Niño. Este interés queda en muchas ocasiones en entredicho, a pesar de que aparezca reflejado en diferentes documentos reguladores ${ }^{14}$. De hecho, si la decisión de si debe o no acompañar el hijo o la hija a la madre en su estancia en prisión se basase realmente en este derecho, es evidente que el interés superior del menor sería evitar el ingreso de la madre en un medio cerrado de cumplimiento de condena, poniendo a disposición del caso todos los medios existentes en cuanto a medidas alternativas se refiere. Son múltiples los estudios que denuncian lo inapropiado de la prisión para las mujeres que han de cumplir una condena ${ }^{15}$, así como la desproporción en la duración de los encierros en relación con el bien que persiguen proteger, la

14. En este caso, el documento más pertinente de señalar es el Reglamento Penitenciario, que, en su capítulo $\mathrm{V}$, regula el internamiento en unidades de madres atendiendo al interés superior del niño o de la niña. Además, España, como país que ha firmado y ratificado la Convención de los Derechos del Niño, está obligado a velar por su expreso cumplimiento, siendo el interés superior del menor un principio garantista de ello, con lo cual precisa de una atención especial.

15. El principio de inclusión de la perspectiva de género en toda política o acción, o principio de transversalidad de género, constituye una de las herramientas de la Comisión Europea para cumplir esta función de igualdad de la Unión (Cruells e Igareda, 2005: 90-91), tarea en la que, como hemos visto, el Estado español sigue presentando grandes deficiencias, al menos en materia penitenciaria. 
mayor dureza al aplicar la dispersión de forma sistemática para ellas y cómo sus condenas afectan a sus hijos e hijas, tanto dentro como fuera de la prisión. Además, en la actualidad, se está aplicando el programa de tratamiento penitenciario llamado Módulos de Respeto con muchas de las mujeres encerradas, pero de nuevo no se lleva a cabo desde un análisis global del encarcelamiento femenino, sino que ha conllevado una mera transposición de las premisas de su aplicación para la población penitenciaria masculina. Esto, unido a las tradicionales condiciones del encarcelamiento femenino en nuestro país, con unas peores condiciones y un vacío respecto a sus necesidades específicas, influido por la escasez de módulos y prisiones de mujeres, la falta de clasificación, etc., ha provocado que ni siquiera ciertos estándares de aplicación estén hoy mínimamente satisfechos en el caso femenino. Es necesario, dicen Ballesteros y Almeda, hacer emerger estas ambigüedades y contraposiciones en un análisis que se articule con un enfoque feminista e interseccional que permita dar cuenta de las particularidades de la presencia conjunta de variables como extranjería, presencia de drogodependencias, enfermedad mental, discapacidades, diversidad sexual o diferencia étnica (Ballesteros y Almeda, 2015: 180-181), junto con maternidad, añadiríamos desde este estudio.

Además el análisis de la cuestión, plantea la posibilidad de que esta situación alimente una "espiral de la exclusión» de la que formen parte estos hijos e hijas de las mujeres presas (y, en general, de las personas presas), con lo que se perpetuarían las diferencias de clase, la marginalidad y, con ello, la institucionalización de diferentes formas: relación con el sistema de protección, de reforma e incluso con la cárcel de adultos. No parece una idea alejada de lo común cuando se observa que un gran número de mujeres presas en su etapa adulta había pasado por este tipo de situaciones previas en su infancia y juventud ${ }^{16}$. Así, la veracidad de la protección del interés superior del niño se cuestiona, ya que, tal y como argumenta el informe de Save The Children:

[...] la interpretación de este concepto es arbitraria, puesto que es infrecuente encontrar en las resoluciones una motivación de la decisión adoptada, que incluya una explicación completa del modo en que la misma contribuye a la realización de este interés «superior» que debe primar [...] erróneamente se equipara la indeterminación del concepto a la falta de indicadores [...] sin embargo, existen. Son los principios rectores de la CDN [...] como el resto de documentos internacionales de derechos humanos. La indeterminación del término plantea la exigencia de conocer su situación individualizada de manera exhaustiva. Identificar todos los derechos del niño o de la niña que se encuentran afectados y determinar, en base a la plena protección, promoción y respeto de los mismos, qué solución se ajusta más a su plena realización. (Rodríguez et al., 2012: 24-25)

Es evidente, dados los resultados del estudio, que no puede darse por respetado un proceso que incluya todos estos aspectos, ni en la decisión de que

16. Cuatro de cada diez mujeres presas en el período comprendido entre los años 2000 y 2003 habían pasado previamente por instituciones de tutela para menores (EDIS, 2005). 
el niño o la niña acompañe o no a su madre, ni en la evaluación que precisa la adecuación de este medio a que residan allí menores.

Son muchos los derechos que, fruto del análisis, se constata quedan vulnerados en distintos grados. Se trata entonces de una socialización que se está llevando en un medio hostil, donde existe y se ejerce una violencia tanto simbólica como real. Pero la situación actual en el centro que permanece albergando a madres con sus hijos e hijas menores de tres años en la Comunidad de Madrid en este momento no presenta una mejor situación, sino un empeoramiento y un recorte aún mayor de los derechos de estos menores, como constata el informe publicado en 2015 por parte de familiares de madres allí encerradas, que incluye un escrito de las mujeres presas, informes de pediatras y análisis de la situación de psicólogos docentes en la Universidad del País Vasco ${ }^{17}$. En este dosier, se confirma lo también recogido en nuestro análisis acerca de cómo la forma de las visitas ha sufrido un retroceso al volverse a realizar en un locutorio (tras un cristal, en un pequeño espacio y sin que el niño o la niña escuche la voz de los parientes, a excepción de si se le acerca el auricular), y es más, los vis a vis familiares han pasado a realizarse en una pequeña sala no acondicionada y con mala higiene, en vez de tener lugar en un jardín dispuesto anteriormente para ello (lo que incide en el hecho de que este tipo de visitas suponen cuatro horas en las que las criaturas se sienten aún más encerradas, con lo que incluso llegan a no querer ir). Otras cuestiones denunciadas en este informe son las siguientes: la dificultad que encuentran las madres para lograr que las funcionarias permitan la salida de los niños y de las niñas al jardín que esta cárcel tiene para dicho cometido, el empeoramiento de la alimentación de los menores, que hasta los 18 meses está únicamente compuesto por purés y que, a partir de este momento, no consta de un menú adaptado, sino del mismo que se proporciona a las madres, de baja calidad y con una presencia excesiva de alimentos precocinados. Son estas las tres cuestiones más urgentes a resolver desde el punto de vista de las madres, aunque en el dosier se apuntan otras tantas que necesitan ser solucionadas, dado el impacto en sus hijos e hijas (el uso de la megafonía incluso en horas de sueño de los menores, la no eliminación de elementos peligrosos, las dificultades que suponen las restricciones de sus salidas del centro para la correcta relación con sus padres y otros familiares, la escasez de material de puericultura y el deterioro del existente, la persistencia de la realización de cacheos en su presencia, etc.). En definitiva, en palabras de mujeres que están cumpliendo condena allí desde hace años, se ha endurecido la situación en una cárcel donde, en época de la anterior directora de Instituciones Penitenciarias Mercedes Gallizo, sí se tenía en cuenta la presencia de niños y niñas en relación con algunas medidas. Y es que la prisión como herramienta política

17. Se trata de un dosier publicado solo a través de Internet. Se titula Dossier Módulo de madres de la prisión de Aranjuez. Vulneración de derechos y puede consultarse en la dirección siguiente: http://www.osalde.org/website/articulos/vulneraci\%C3\%B3n-de-derechos-delas-madres-e-hijosas-en-la-prisi $\% \mathrm{C} 3 \% \mathrm{~B} 3 \mathrm{n}$-de-aranjuez 
obedece y se ve afectada por cada cambio de gobierno, cuestión poco eficiente en un camino que, en principio, debería buscar el fin que persigue en el reglamento oficial la privación de libertad, esto es, la reinserción y reeducación de las personas. Así, no es solo preciso plantear unas mejoras en las condiciones de vida de estos menores y, en general, de las personas que cumplen condena en prisión, sino que lo que es necesario replantear es precisamente la función real que cumple la cárcel desde sus inicios hasta el día de hoy y cuáles son sus verdaderas condiciones a nivel social y en referencia a los derechos humanos.

\section{Referencias bibliográficas}

Aguilera, Margarita (2011). «Mujeres presas: La doble condena». En: Manzanos, César (coord.). Politicas sociales para abolir la prisión. Vitoria-Gasteiz: Ikusbide.

Alejos, Marlene (2005). Bebés y niñoslas pequeñas que residen en prisiones [edición digital]. Quaker United Nations Office (QUNO).

Alliance of Non-Governmental Organization on Crime Prevention and Criminal Justice (1987). Children in prison with their mothers. Nueva York: Alliance of NGOS on Crime Prevention and Criminal Justice.

Almeda, Elisabet (2002). Corregir y castigar: El ayer y hoy de las cárceles de mujeres. Barcelona: Edicions Bellaterra

- (2003). Mujeres encarceladas. Barcelona: Ariel.

- (2011). «Privación de libertad y mujeres extranjeras: Viejos prejuicios y nuevas desigualdades». En: AÑaños, Fanny (coord.). Las mujeres en las prisiones: La educación social en contextos de riesgo y conflicto. Barcelona: Gedisa.

Álvarez-Uría, Fernando y Varela, Julia (2009). Sociología de las instituciones: Bases sociales y culturales de la conducta. Madrid: Morata.

Amnistía InTernacional (2013). Hay alternativas: No a la detención de personas inmigrantes. Comentarios al borrador del Gobierno sobre el reglamento de los Centros de Internamiento de Extranjeros. Madrid: Sección española de Amnistía Internacional.

AÑaños, Fanny (coord.) (2011). Las mujeres en las prisiones: La educación social en contextos de riesgo y conflicto. Barcelona: Gedisa.

Arola, Jordi (2010). «Madres en prisión: La disciplina de la maternidad». Viscera, 4, 28-31.

BAEZA, Javier (2011). «Experiencias de apoyo social frente a la intervención penal con personas marginadas». En: Manzanos, César (coord.). Politicas sociales para abolir la prisión. Vitoria-Gasteiz: Ikusbide.

Ballesteros, Ana y Almeda, Elisabet (2015). «Políticas de igualdad en las cárceles del siglo Xxi: Avances, retrocesos y retos en la práctica del encarcelamiento femenino». Praxis Sociológica, 19, 161-186.

Bourdieu, Pierre (1988). La distinción. Madrid: Taurus.

BowLBY, John (1951). Maternal care and mental health. Ginebra: World Health Organization.

Brooker, Liz y Woodhead, Martin (ed.) (2012). Ambientes saludables: Primera infancia. Reino Unido: Child and Youth Studies Group / The Open University. La Primera Infancia en Perspectiva, 8. Serie editada por Martin Woodhead y John Oates.

Cabrera, Pedro (2011). «Exclusión social y prisión: Algunas propuestas para combatirla». En: Manzanos, César (coord.). Politicas sociales para abolir la prisión. Vitoria-Gasteiz: Ikusbide. 
Cabrera, Pedro y Ríos, Julián Carlos (1998). Mil voces presas. Madrid: Universidad Pontificia de Comillas.

Canteras, Andrés (1987). "Cárceles de mujeres en España: Origen, características y desarrollo histórico». Revista de Estudios Penitenciarios, 237, 29-34.

Cappelaere, Geert y Grandjean, Anne (2000). Niños privados de libertad: Derechos y realidades. Madrid: Ministerio de Trabajo y Asuntos Sociales.

Casado, Elena y García, Antonio A. (2008). "La práctica de la observación participante: Sentidos situados y prácticas institucionales en el caso de la violencia de género». En: Gordo López, Ángel y Serrano Pascual, Araceli (coords.). Estrategias y prácticas cualitativas de investigación social. Madrid: Pearson Educación, 47-73.

Catan, Liza (1992). «Infants with mothers in prison». En: Shaw, R. (ed.). Prisoners' children: What are the issues? Londres: Routledge.

Charbonneau, Johanne (2003). Adolescentes et mères: Histoires de maternitè prècoce et soutien du rèseau social. Saint-Nicolas: PUL.

Cruells, Marta e Igareda, Noelia (2005). Mujeres, integración y prisión. Barcelona: Aurea Editores.

Díez Ripollés, José L. (2006). "Algunos rasgos de la delincuencia en España a comienzos del siglo XXI». Revista Española de Investigación Criminológica, 4, 1-19.

EDIS. Equipo de Investigación Sociológica (2005). Realidad social de las mujeres sin techo, prostitutas, ex-reclusas y drogodependientes en España. Madrid: Instituto de la Mujer.

Foucault, Michel (1992). Vigilar y castigar. Madrid: Siglo XXI.

Gaitán, Lourdes (2006). Sociología de la Infancia: Nuevas Perspectivas. Madrid: Síntesis.

Gallego, Manuel; Cabrera, Pedro; Ríos, Julián y Segovia, José Luis (2010). Andar $1 \mathrm{~km}$ en línea recta: La cárcel del siglo XXI que vive el preso. Madrid: Universidad Pontificia Comillas.

Goffman, Erving (1984). Internados: Ensayos sobre la situación social de los enfermos mentales. Buenos Aires: Amorrortu.

Jiménez, Jesús y Palacios, Jesús (1998). Niños y madres en prisión. Desarrollo psicosociobiológico de los niños residentes en centros penitenciarios. Madrid: Ministerio del Interior/Ministerio de Trabajo y Asuntos Sociales.

Juliano, Dolores (2009). "Delito y pecado: La transgresión en femenino». Política y Sociedad, 46 (1 y 2), 79-95.

- (2011). Presunción de inocencia: Riesgo, delito y pecado en femenino. Donostia/San Sebastián: Gakoa Liburuak.

Mayall, Berry (2002). Towards a Sociology for Childhood. Buckingham: Open University Press.

Moreno Torres-SÁnchez, Julieta (2005). El desamparo de menores. Navarra: Aranzadi.

Naredo, María (2007). "Reclusas con hijos/as en la cárcel». En: Almeda, Elisabet y Bodelón, Encarna (ed.). Mujeres y castigo: Un enfoque socio-jurídico y de género. Madrid: Dykinson.

OAKley, Ann (1993). "Women and children first and last: Parallels and diferences between children and women studies». En: Childhood as a Social Phenomenon: Lessons from an International Project. Viena: Centro Europeo. Eurosocial Report, 47, 51-70.

Ochaíta, Esperanza y Espinosa, Ma Ángeles (2004). Hacia una teoría de las necesidades infantiles y adolescentes. Madrid: McGraw-Hill. 
Ríos, Julián (2013). La prisión perpetua en España: Razones de su ilegitimidad ética y de su inconstitucionalidad. Donostia/San Sebastián: Gakoa Liburuak.

Rodríguez, Iván (2006). «Redefiniendo el trabajo metodológico cualitativo con niños: El uso de la entrevista de grupo aplicada al estudio de la tecnología». Empiria [en línea], 12, 65-88. <https://doi.org/10.5944/empiria.12.2006.1135>.

Rodríguez, Virginia; Román, Yolanda y Escorial, Almudena (2012). Infancia y justicia: una cuestión de derechos: Los niños y niñas ante la administración de justicia en España. Madrid: Save the Children España.

UNICEF (2007). Convención sobre los Derechos del Niño. Madrid: UNICEF.

VALVERDE, Jesús (1991). La cárcel y sus consecuencias: La intervención sobre la conducta desadaptada. Madrid: Popular.

Weissgerber, Gislhaine y Delens-Ravier, Isabelle (coord.) (2007). La infancia con el padre o la madre en prisión. Barcelona: Hacer.

YaGǘ Olmos, Concepción (2006). Madres en prisión: Historia de las cárceles de mujeres a través de su vertiente maternal. Granada: Comares.

- (2012). "Políticas de género y prisión en España». En: Del VAL, Consuelo y Viedma, Antonio (eds.). Condenadas a la desigualdad: Sistema de indicadores de discriminación penitenciaria. Barcelona: Icaria. 